\title{
The factors correlated to nurses' decision activating code blue team in hospital
}

\author{
Ekwantoro $^{1}$, Kuswantoro Rusca Putra ${ }^{2}$, Setyoadi ${ }^{3}$ \\ ${ }^{1}$ Kertosono Hospital, Indonesia \\ ${ }^{2,3}$ Faculty of Medical Brawijaya University, Indonesia
}

\begin{tabular}{l} 
Article Info \\
\hline Article history: \\
Received Jul 8, 2020 \\
Revised Dec 7, 2020 \\
Accepted Jan 2, 2021 \\
\hline
\end{tabular}

\section{Keywords:}

Code blue

Cognition

Decision-making

Experience

Organizational culture

\begin{abstract}
The success and hindrances of the blue-code activation were based on nurses' readiness to request assistance once a patient's clinical condition decreases. This research aimed to determine the nurses' hindrance factors in making the blue code activation at hospitals. This research is analytical-observational with a cross-sectional approach. The samples consisted of 93 nurses taken randomly. The data were collected by questionnaire from March until April 2020 at one of the Nganjuk Government Hospitals. The Pearson test result showed a correlation between experience with p-value 0.022 , education with a p-value 0.000 , cognition with p-value 0.006 , and organizational culture with a $\mathrm{p}$-value 0.000 toward decision-making $(\mathrm{p}$-value $<0.05)$. The multiple linear regression multivariate analysis shows an Exp. value (B) of education is 0.292 , experience with a value 0.178 , cognition with a value 0.194 , and cultural organization with a score of 0.425 . Thus, it could be concluded that the organizational culture was the most dominant factor of the nurses' decision making. The hindrances and success of the nurses' decision-making are based on the nurses' characteristics, such as cognition, communication skill, and collaboration skill. The support from the leader of an organization would influence nurses' confidence dealing with patients' health.
\end{abstract}

This is an open access article under the CC BY-SA license.

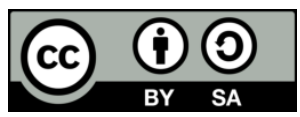

\section{Corresponding Author:}

Ekwantoro

Nurse Emergency Room, Kertosono Hospital

Jl. Panglima Sudirman 16 Kertosono, Nganjuk, East Java, Indonesia

Email: exwanagata35@gmail.com

\section{INTRODUCTION}

Code blue is a term used by the whole world hospitals to tell cardiac or respiratory arrest emergency state conditions [1]. This code was first introduced around the 1990s in Bethany Medical Center, Kansas. The purpose of a code blue is to intervene in cardiac-arrested or critically ill patients administered by the code blue team at hospitals [2]. A code blue team consists of a doctor, a nurse, and other staff who have emergency skills [3]. Code blue team, in some countries, is still combined with a rapid response team. It is due to insufficient human resource availability [4]. However, the function and purpose of this team are the same. It is to save patients from suffering from cardiac arrest.

This code blue activation implementation influences the service quality and improves the patients' life quality at the hospital [5]. The applied intervention promoted by the code blue team for any critical patients could increase their survivability until $23 \%$. For cardiac arrest patients, it could reach a percentage of $11.13 \%$ [6]. Other studies mention that a code blue activation could decrease $18-19 \%$ mortality cases due to cardiac arrest in inpatient services [7,8].

The nurses' decision making is deemed important when there is a critical condition of a patient. When a nurse notices a changing condition of a patient, he should make a code blue team call for the sake of the patient's safety. The nurses' unreadiness partially causes the hindrances in activating the code blue team 
is requesting aid dealing with the clinical patient's condition decrease [9]. The nurses in activating the code blue team are depended on their skills in making a decision based on their cognition and experience to prevent further complications and mortality [10]. Other concerning factors are organizational culture in each unit [11]. Unsupported organizational culture for nurses to activate the code blue team influences decisionmaking confidence [12]. Organizational culture also functions as a guideline. When a decision-making process does not align with the organizational spirit, then the decision cannot run maximally [13]. This research aims to analyze the nurses' correlating factors in making the blue code activation at hospitals.

\section{RESEARCH METHOD}

\subsection{Study design}

This study was an analytic-observational study with a cross-sectional approach. The samples consisted of 93 nurses who were taken randomly. Data collection was carried out by means of a questionnaire from March to April 2020 at one of the Nganjuk Government Hospitals, East Java, Indonesia. This research had been deemed ethically feasible from the research-ethics commission of Medicine Faculty of Brawijaya University Malang, Number 58/EC/KEPK-S2/03/2020.

\subsection{Instruments}

A questionnaire collected the data. This research applied indicators made by Jenkins et al. [14] to deal with the cognitive questionnaire. On the other hand, the questionnaire for organizational culture was based on Robbins and Judge [15], and the decision-making questionnaire was based on The Nurse Decision Making Instrument developed by Lauri and Salanterä [16]. All questionnaires had been tested in terms of their validity and reliability. The questionnaire validity test was done by Pearson Product Moment (r). The instruments were deemed valid when the $r$ count $>r$ table $(0.468)$. The cognitive questionnaire validity test results showed the $\mathrm{r}$ count ranged from 0.479 to 0.595 , the organizational culture ranged from 0.472 to 0.819 , and the $r$ count of the decision-making ranged from 0.474 to 0.81 . The decision of the validity test for all questionnaires was valid ( $\mathrm{r}$ count>0.468). The Cronbach's alpha score of the reliability test is higher than 0.60 . The results of the reliability test for whole questionnaires, cognitive (0.731), organizational culture (0.876), and decision making (0.844) obtained a score of Cronbach's alpha>0.060. Thus, all questionnaires were reliable.

\subsection{Data analysis}

The data analysis applied the Pearson test to find out the inter-variable correlations. On the other hand, multiple linear regressions were applied to find out the most influential decision-making factor. In this research, the data was analyzed by IBM statistical package for the social sciences (SPSS) version 26.0 for Windows.

\section{RESULTS AND DISCUSSION}

\subsection{Respondents' characteristics}

The findings showed from 93 condescend, nurses that most of them were averagely aged 34.07 years old $(\mathrm{SD} \pm 6.97)$. Most of the respondents were females, 57 participants $(61.3 \%)$. The latest education levels of the respondents were Diploma III, 70 participants $(75.3 \%)$ with an average of years of service was 11 years $(\mathrm{SD} \pm 7.37)$ as shown in Table 1 .

Table 1. The respondent distribution $(\mathrm{n}=93)$

\begin{tabular}{|c|c|c|c|}
\hline \multicolumn{2}{|c|}{ Characteristics } & Mean \pm SD & Min-max \\
\hline \multicolumn{2}{|l|}{ Age (years) } & $34 \pm 6.97$ & $24-48$ \\
\hline \multicolumn{2}{|c|}{ Experience (years) } & $11 \pm 7.37$ & $1-24$ \\
\hline \multicolumn{2}{|c|}{ Characteristics } & Frequency (n) & Percentage \\
\hline \multirow[t]{2}{*}{ Sex } & Male & 36 & $38.7 \%$ \\
\hline & Female & 57 & $61.3 \%$ \\
\hline \multirow[t]{2}{*}{ Education } & Diploma & 70 & $75.3 \%$ \\
\hline & Bachelor & 23 & $24.7 \%$ \\
\hline
\end{tabular}

The average score shows that mature individuals dominate most of the participants. Therefore, their decision-making got better due to their matureness [17]. When an individual gets older, then his experience would cumulatively increase [18]. This matureness in an individual's decision making is determined by psychological matureness. It was directly correlated to the ages of the nurses. The more mature and the more obtained experiences, the wiser an individual would be to decide. The education in this research was the 
result of the obtained learning from the college or formal educations. This research results showed the educational factor influenced the nurses' decision making in activating the code-blue team. This research is in line with [19]. It found that education positively influenced the decision-making process. Education could also influence the awareness of caring for the patients and making the best decision [20]. The nurse decisionmaking combined both theories the nurses obtained during their education and the real conditions of the patients they handled [21].

The nurse experience will provide valuable information about the decision-making process. The nurse's experience could improve the intuitive decision making, although intuitive decision making might not be better or worse than the rational or other decisions [22]. The nurses' cumulative experience would be information and science to make sufficient decision dealing with the patients' conditions [23].

\subsection{The nurses' decision making in activating the code blue team}

The nurses' decision-making in the activating code blue team showed that most nurses had an intuitive pattern. There were 67 respondents $(72 \%)$. In the dimension or the process of making decision, the average data collection is 20.22 (SD+1.99), problem identification is $20.6(\mathrm{SD}+2.11)$, the planning activity is 21.09 (SD+2.77), and the implementation or evaluation is 20.79 (SD+2.65) as shown in Table 2.

In this research, decision-making is the nurse's decision to activate the code blue team based on hospitalized patients' clinical condition decrease. Our findings showed that most of the nurse decisionmaking had the intuitive pattern $72 \%$. The intuitive decision making is an immediate and accurate decision based on an individual's cognition and experience [24]. The nurse's experience could improve the intuitive decision making although the intuitive decision making might not better or could be worse than the analytic or other decisions [22]. The cumulative experience of the nurses would be information and knowledge to take sufficient decision dealing with the patients' conditions [23].

Other research findings showed that nurses did not apply their intuitive decision for the whole nursing care process. This pattern was used to support a critical patient assessment [25]. The intuitive decision-making process tended to be applied in the planning process after collecting the data and identifying problems. Other findings showed that intuitive decision-making was assumed not worthy concept and not reliable to be applied in nursing care science. It was due to its abstract and multi interpretation natures. Thus, it is not legit $[26,27]$.

Table 2. The nurses' decision making $(n=93)$

\begin{tabular}{lcc}
\hline \multicolumn{1}{c}{ The decision making pattern } & Frequency & Percentage \\
\hline Intuition & 67 & $72 \%$ \\
Quasi-rational & 21 & $22.6 \%$ \\
Analysis & 5 & $5.4 \%$ \\
The process of making a decision & Mean \pm SD & Min-max \\
The data collection & $20.2(1.99)$ & $16-18$ \\
Problem identification & $20.6(2.11)$ & $14-26$ \\
The activity plan & $21.0(2.77)$ & $14-28$ \\
The implementation and evaluation & $20.7(2.65)$ & $14-29$ \\
\hline SD $=$ standard of deviation & &
\end{tabular}

$\mathrm{SD}=$ standard of deviation

\subsection{The cognitive influence toward decision-making}

In Table 3, the cognitive factor dealing with the code blue activation has an average score of 8.7 ( $\mathrm{SD} \pm 1.01)$. The Parameters or sub-variables of the cognition are awareness of when a code blue call is needed with an average score $2.70(\mathrm{SD} \pm 0.51$ ), the cognition dealing with a code blue policy, $2.6(\mathrm{SD} \pm 0.58)$, awareness of patient transport to the intensive care with $1.84(\mathrm{SD} \pm 0.38)$, and the critical patient management with $1.6(\mathrm{SD} \pm 0.55)$. The Pearson statistics test showed that there was a significant influence between cognitive factor and the decision making with $\mathrm{r}$ score $=0.238, \mathrm{p}=0.06$ ( $\mathrm{p}$-value $<0.05$ ).

Table 3. The cognitive influence in the nurses' decision making $(\mathrm{n}=93)$

\begin{tabular}{lcccc}
\hline \multicolumn{1}{c}{ The variable data } & Mean \pm SD & Min-max & r & p-score \\
\hline Cognition & $8.7 \pm 1.01$ & $6-10$ & 0.283 & 0.006 \\
Cognitive parameters & & & \\
The cognition covers awareness of when the code blue call is needed & $2.70 \pm 0.51$ & $1-3$ & 0.133 & 0.203 \\
The cognition concerning with the code blue policy & $2.6 \pm 0.58$ & $0-3$ & 0.098 & 0.349 \\
The awareness of patient transport to intensive care & $1.84 \pm 0.38$ & $0-2$ & 0.210 & 0.043 \\
The clinical patient management & $1.6 \pm 0.55$ & $0-2$ & 0.087 & 0.405 \\
\hline SD
\end{tabular}

$\mathrm{SD}=$ standard of deviation

Int. J. Public Health Sci. Vol. 10, No. 1, March 2021: 202 - 206 
The cognition or knowledge in activating the code blue team analyzes how nurses understand and manage patients with critically ill conditions and use the code blue team [12]. This research showed the educational factor influenced the nurses' decision making in activating the code-blue team. Cognitive management has an essential implication for decision-making in various situations. The obtained knowledge from various sources, either from experience or other sources, could be based on decision-making [28]. Intuitive decision making is based on focused-understanding knowledge, and it often obtains an accurate decision [29]. A poor decision making could be caused by limited knowledge of a nurse. Novice nurses mostly experience this insufficient knowledge in activating the code blue team because they encounter decision-making situations [30].

\subsection{Organizational culture influence decision making}

The results show that organizational culture average score is $60.18(\mathrm{SD} \pm 13.3)$. The parameters of organizational culture covers the innovation mean score, 6.9 ( $\mathrm{SD} \pm 0.85)$, Detail-oriented $6.9(\mathrm{SD} \pm 1.34$ ), outcome-oriented 10.6 (SD \pm 1.32$)$, people oriented $10.4(\mathrm{SD} \pm 1.36)$, team oriented $10.5(\mathrm{SD} \pm 0.91)$, aggressive $10.3(\mathrm{SD} \pm 1.23)$ and the stable average score $10.4(\mathrm{SD} \pm 1.23)$. The Pearson statistics test between the organizational culture and the decision-making had a significant correlation with the cognitive score $(0.006<0.05)$ as shown in Table 4. Organizational culture in this research is correlated to the policy of the concerning leaders in deciding. Thus, it would influence patients' safety [20]. The organizational support could be empowerment and development in utilizing the facilities, either the rapid response team or the code blue team [31]. The results show a significant correlation between the organizational culture and the nurse's decision to activate the code blue team in the hospital. All indicators (innovation, detail-oriented, outcomeoriented, people-oriented, team-oriented, aggressiveness, and stable) in the organizational culture could support the nurses' decision-making to activate the code-blue team. The influence of a unit's organizational culture has a role in supporting decision-making when there is a problem or changing patient care [24, 31].

The results of multiple linear regression analysis test shows that the influential factors of the nurses' blue code activation decision are cognition $(\mathrm{p}=0.021)$, experience $(0.081)$, education $(\mathrm{p}=0.001)$, and organizational culture $(\mathrm{p}=0.000)$. The organizational culture factor was the most dominant in the decision making with the Exp (B) 0.425 as shown in Table 5.

Table 4. The organizational culture influence the nurses' decision making ( $\mathrm{n}=93)$

\begin{tabular}{lcccc}
\hline \multicolumn{1}{c}{ The variable data } & Mean \pm SD & Min-Max & r & p-score \\
\hline Organizational culture & $60.18 \pm 13.3$ & $29-76$ & 0.515 & 0.000 \\
The organizational culture indicators & & & & \\
$\quad$ Innovation & $6.9 \pm 0.85$ & $5-8$ & 0.169 & 0.105 \\
Detail-oriented & $6.9 \pm 1.34$ & $8-12$ & 0.329 & 0.001 \\
Outcome-oriented & $10.6 \pm 1.32$ & $8-12$ & 0.307 & 0.003 \\
People-oriented & $10.4 \pm 1.36$ & $8-12$ & 0.456 & 0.000 \\
Team-oriented & $10.5 \pm 0.91$ & $5-12$ & 0.460 & 0.000 \\
Aggressive & $10.3 \pm 1.23$ & $8-13$ & 0.392 & 0.000 \\
Stable & $10.4 \pm 1.23$ & $8-12$ & 0.245 & 0.000 \\
\hline
\end{tabular}

Table 5. The multiple linear regression model

\begin{tabular}{ccc}
\hline Model & Unstandardized Exp (B) & Value \\
\hline Constanta & 33.738 & 0.000 \\
Cognition & 0.194 & 0.021 \\
Years of Service & -0.146 & 0.081 \\
Education & 0.292 & 0.001 \\
Organizational Culture & 0.425 & 0.000 \\
\hline
\end{tabular}

\section{CONCLUSION}

The intuitive decision making to activate nurses had mostly applied the code-blue team. It was based on their experience and knowledge while caring for the patients at the hospital. The correlated factors in decision making were such as cognition, experience, education, and organizational culture. They became successful factors in calling the code-blue team. Organizational culture becomes the most dominant factor in the decision-making of code-blue team activation. Thus, the support from an organization's leader would influence the nurses' confidence in making a decision related to the patients' health.

\section{ACKNOWLEDGEMENTS}

Thanks to the dean of the Kertosono Hospital, Nursing Master Program of Brawijaya Malang University, and all parties that assisted this research. 


\section{REFERENCES}

[1] S. K. Pattnaik, et al., "Code Blue Protocol: Observation and Analysis of Results Over Last 3 Years in A New Tertiary Care Hospital," Intensive Care Medicine Experimental, vol. 3, no. Suppl 1, p. A205, 2015.

[2] K. M. Al-Aboud, D. M. Al-Aboud, "Hospital Emergency Codes. An Appraisal," Saudi Medical Journal, vol. 31, no. 12 , p. $1377,2010$.

[3] J. W. Price, et al., "Code Blue Emergencies: A Team Task Analysis and Educational Initiative," Canadian Medical Education Journal vol. 3, no. 1, pp. e4-e20, 2012.

[4] M. F. Rashid, et al., "Evaluation of Rapid Response Team Implementation in Medical Emergencies: A Gallant Evidence Based Medicine Initiative In Developing Countries for Serious Adverse Events," International Journal Critical Illness Injury Science, vol. 4, no. 1, pp. 3-9, 2014.

[5] D. Jones, et al., "The Rapid Response System and End-of-Life Care," Current Opinion Critical Care, vol. 19, no. 6, pp. 616-623, 2013.

[6] S. Monangi, et al., "Analysis of Functioning and Efficiency of A Code Blue System In A Tertiary Care Hospital," Saudi Journal Anesthesia, vol. 12, no. 2, pp. 245-249, 2018.

[7] P. J. Sharek, et al., "Effect of A Rapid Response Team on Hospital-Wide Mortality and Code Rates Outside The ICU In A Children's Hospital,” Jama, vol. 298, no. 19, pp. 2267-2274, 2007.

[8] M. Sabahi, et al., "Efficacy of A Rapid Response Team on Reducing The Incidence and Mortality of Unexpected Cardiac Arrests," Trauma Monthly, vol. 17, no. 2, pp. 270-274, 2012.

[9] S. D. Marshall et al., "Why Don’t Hospital Staff Activate The Rapid Response System (RRS)? How Frequently Is It Needed and Can The Process Be Improved?," Implementation Science, vol. 6, no. 1, p. 39, 2011.

[10] H. Hogan, et al., "Effectiveness of ways to improve detection and rescue of deteriorating patients," British Journal Hospital Medicine (Lond)., vol. 78, no. 3, pp. 150-159, 2017.

[11] S. Kitto et al., "Rapid Response Systems and Collective (In) Competence: An Exploratory Analysis of Intraprofessional and Interprofessional Activation Factors," Journal Interprofessional Care, vol. 29, no. 4, pp. 340-346, 2015.

[12] K. S. Astroth, et al., "A Measure of Facilitators and Barriers To Rapid Response Team Activation," Applied Nursing Research, vol. 33, pp. 175-179, 2017.

[13] W. L. Chua, M., et al., "Factors Influencing The Activation of The Rapid Response System for Clinically Deteriorating Patients By Frontline Ward Clinicians: A Systematic Review," Journal International Quality Health Care: vol. 29, no. 8, pp. 981-998, 2017.

[14] S. H. Jenkins, K. S. Astroth, and W. M. With, "Non-Critical-Care Nurses' Perceptions of Facilitators and Barriers To Rapid Response Team Activation.," Journal Nurses Professional Devolepment, vol. 31, no. 5, pp. 264-270, 2015.

[15] S. Robbins, T. Judge, "Organizational behavior," 12 ed., Jakarta: Salemba Empat, 2008.

[16] S. Lauri, S. Salanterä, "Developing An Instrument to Measure and Describe Clinical Decision Making in Different Nursing Fields," Journal Professional Nursing, vol. 18, no. 2, pp. 93-100, 2002.

[17] W. J. Muntean, "Nursing clinical decision-making: A literature review," NCSBN Exec. Summ., pp. 1-24, 2012.

[18] S. Notoatmodjo, "Health Promotion, Theory and Applications," Jakarta: Rienka Cipta, 2012.

[19] N. Bakalis, G. S. Bowman, and D. Porock, "Decision Making in Greek and English Registered Nurses in Coronary Care Units," International Journal Nursing Studies, vol. 40, no. 7, pp. 749-760, 2013.

[20] L. Stubbings, W. Chaboyer, and A. McMurray, "Nurses' Use of Situation Awareness In Decision-Making: An Integrative Review,” Journal Advanced Nursing, vol. 68, no. 7, pp. 1443-1453, 2012.

[21] Y. Purwanto, "The Decision-Making Behavior of Nurses and Paramedics In Emergency Situation," Jurnal Peneliti Hum., vol. 6, no. 1, pp. 40-58, 2005.

[22] J. E. Pretz and V. N. Folse, "Nursing Experience and Preference for Intuition In Decision Making.," Journal Clinical Nursing, vol. 20, no. 19-20, pp. 2878-2889, 2011.

[23] H. M. Hodgetts, et al., "See No Evil: Cognitive Challenges of Security Surveillance and Monitoring," Journal of Applied Research in Memory and Cognition, vol. 6, no. 3, pp. 230-243, 2017.

[24] A. Mohammed, et al., "Knowledge Management, Decision-Making Style and Organizational Performance," Journal Innovation Knowledge, vol. 4, no. 2, pp. 104-114, 2017.

[25] Ramezani-Badr, Nasrabadi, Y. Z. Taleghani, "Strategies and Criteria for Clinical Decision Making In Critical Care Nurses: A Qualitative Study," Journal Nursing Scholarship, vol. 41, no. 4, pp. 351-358, 2010.

[26] P. Hassani, et al., "Use of Intuition By Critical Care Nurses: A Phenomenological Study," Advances Medical Education Practice, vol. 7, pp. 65-71, Feb. 2016.

[27] M. Smith, J. Higgs, E. Ellis, Factors Influencing Clinical Decision Making, 2008, pp. 89-100.

[28] Joshi, “A Framework to Study Knowledge Management Behaviours During Decision Making," Journal University Librarians Association Sri Lanka, vol. 12, pp. 68-79, 2011.

[29] B. Simmons, "Clinical Reasoning: Concept Analysis," Journal Advanced Nursing, vol. 66, no. 5, pp. 1151-1158, 2010.

[30] P. R. Ebright, et al., "Themes Surrounding Novice Nurse Near-Miss and Adverse-Event Situations," Journal Nursing Administration, vol. 34, no. 11, pp. 531-538, 2004.

[31] S. Linda, Leach, A. M. Mayo, "Rapid Response Teams: Qualitative Analysis of Their Effectiveness," American Journal Critical Care, vol. 22, no. 3, pp. 198-210, 2013. 